\title{
Article \\ The EcoMobileum: Experiencing the World of Environmentally Friendly Urban Mobility
}

\author{
Oliver Schwedes ${ }^{1}$, Konrad Otto-Zimmermann $^{2}$
}

1 Technische Universität Berlin; oliver.schwedes@tu-berlin.de

2 The Urban Idea; konrad@theurbanidea.com

\begin{abstract}
With its sights set on sustainable development, transport policy finds itself confronted with the challenge of convincing people to abandon the current path of growth and instead use small, slower vehicles with a reduced range in the future. This sustainable mobility paradigm needs to shift people's mental structure, still shaped by the private car, to attractive alternatives. Many products classified as vehicles, but smaller in scale than the "car" already exist, but remain unknown, nor can they be tried out. In light of this situation, the German Federal Environmental Foundation has supported a feasibility study to explore the establishment of a World of Experience (Erlebniswelt) of sustainable urban mobility - the EcoMobileum ${ }^{\oplus}$. The paper presents the scientifically founded concept based on the approach of 'imagineering' to open up the horizons of a new culture of mobility in order to get people excited about the transformation of mobility.
\end{abstract}

Keywords: World of Experience; Micromobility, EcoMobileum, Sustainable Mobility Paradigm, Imagineering, Education for Mobility

\section{Introduction}

The transport sector has a unique feature: compared to all other sectors energy consumption and the associated $\mathrm{CO}_{2}$ emissions in the transport sector have been rising steadily since 1990. With respect to the overall goal of carbon neutrality in 2050 so far the transport sector has not contributed at all [1]. A close analysis reveals the tight interconnection between transport and economic growth, which was particularly evident in the global financial and economic crisis in 2008 (cf. Fig. 1). 


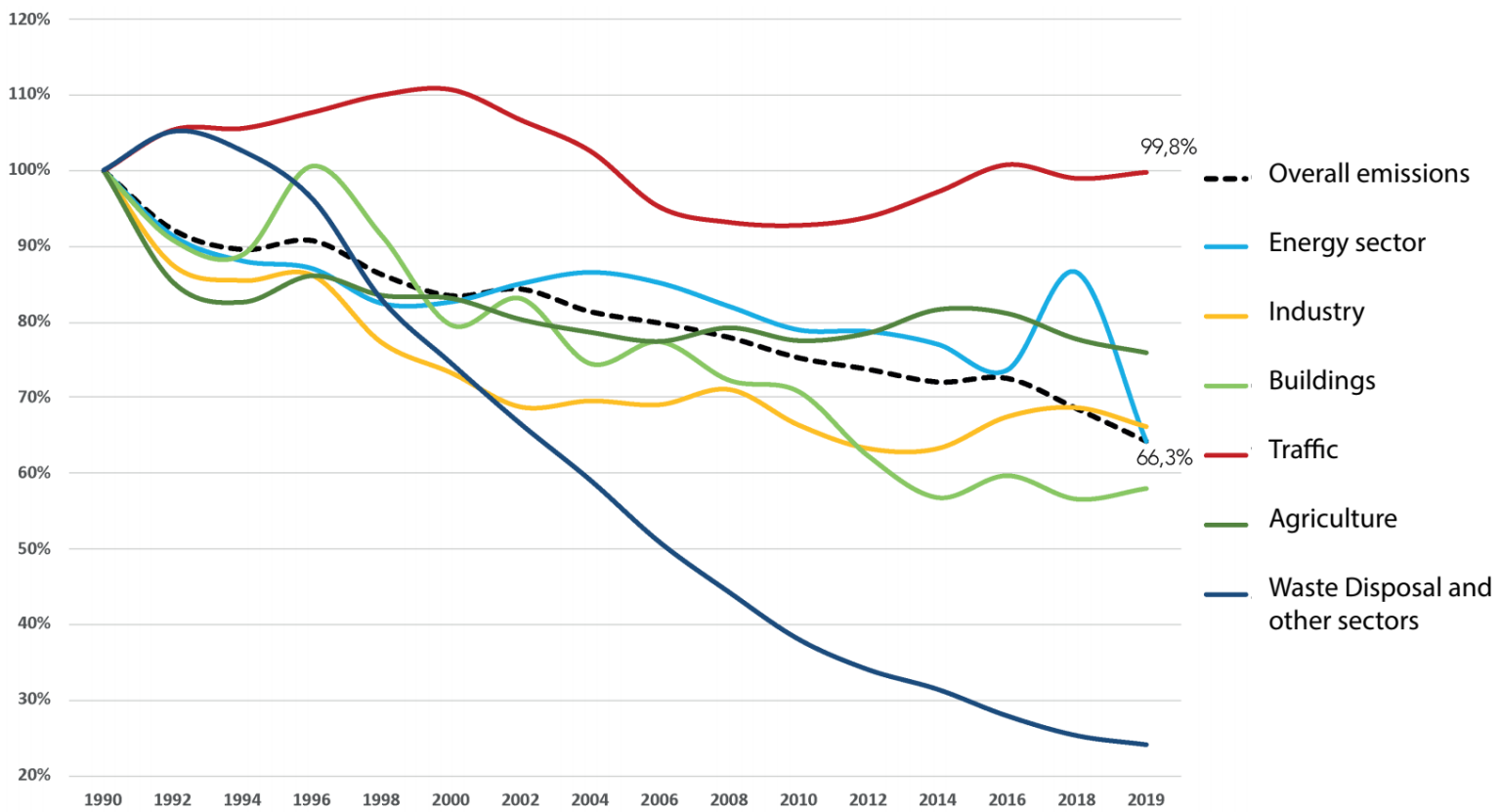

Figure 1: $\mathrm{CO}_{2}$ Emissions in Germany by Sector [1].

This interconnection is once again being revealed by the current global economic crisis resulting from the Corona pandemic, as a consequence of which the volume of traffic is decreasing and transport-related emissions are falling. A year ago, observers were already pointing out that Germany could thus still achieve the climate targets it had set for 2020 [2].

Experience in the wake of the financial and economic crisis of 2008 shows, however, that traffic growth resumes with economic recovery. As a result, the growth in traffic in recent decades has repeatedly eroded and more than negated the gains in efficiency achieved through technical innovations. Even allowing for the exhaust gas manipulations of German automobile companies, motor development over the last decades has contributed to the fact that motor vehicles today consume considerably less fuel than they did twenty years ago. Nevertheless, technical innovations in engine development have not led to lower $\mathrm{CO}_{2}$ emissions. This underscores the basic insight of transport research that sustainable transport development cannot be achieved through technical innovations alone. Rather, social innovations are also necessary - in other words, people must also change their mobility behaviour [3].

Along with the above-mentioned growth in traffic and the associated $\mathrm{CO}_{2}$ emissions, one of the central challenges currently facing transport and urban planners is the increasing land consumption due to infrastructure projects, especially in urban centres. For it is not only the case that traffic activity is growing, i.e. the length of the distances travelled and the number of registered private automobiles continue to rise $[4,5]$ - in addition, vehicles of the same model have been getting bigger and heavier across all vehicle classes for years (cf. Fig. 2). 


\begin{tabular}{|c|c|c|c|c|c|c|c|c|}
\hline & $\begin{array}{c}\text { Year of } \\
\text { Manufacture }\end{array}$ & $\begin{array}{c}\text { Dimensions } \\
\mathrm{L} \times \mathrm{W} \times \mathrm{H} \\
(\mathrm{mm})\end{array}$ & $\begin{array}{c}\text { Weight } \\
(\mathrm{kg})\end{array}$ & $\begin{array}{c}\text { Engine } \\
\text { Performance } \\
(\text { Horsepower) }\end{array}$ & $\begin{array}{c}\text { Fuel } \\
\text { Consumption } \\
(\text { Litres })\end{array}$ & $\begin{array}{c}\mathrm{CO} 2 \\
(\mathrm{~g} / \mathrm{km})\end{array}$ & $\begin{array}{c}\text { Maximum } \\
\text { Speed } \\
(\mathrm{km} / \mathrm{h})\end{array}$ & $\begin{array}{c}\text { Purchase Price } \\
(\text { Euro) }\end{array}$ \\
\hline Golf II & 1990 & $3985 \times 1665 \times 1415$ & $845-1020$ & $55-90$ & $8,5-10$ & $146-272$ & $150-175$ & $13.490,-$ \\
\hline Golf IV & 2000 & $4149 \times 1735 \times 1439$ & $1050-1477$ & $75-125$ & $6,6-7,9$ & $158-199$ & $170-195$ & $15.175,-$ \\
\hline Golf VI & 2010 & $4199 \times 1779 \times 1461$ & $1217-1541$ & $80-160$ & $6,4-7,3$ & $149-170$ & $175-220$ & $23.610,-$ \\
\hline Golf VII & 2012 & $4255 \times 1799 \times 1442$ & $1205-1272$ & $86-180$ & $4,3-7,8$ & $100-155$ & $180-220$ & $24.775,-$ \\
\hline Golf VIII & $2019 / 20$ & $4284 \times 1789 \times 1491$ & $1255-1465$ & $90-150$ & $3,4-4,8$ & $89-109$ & $188-224$ & $19.995-32.790,-$ \\
\hline
\end{tabular}

Figure 2: Increase in the size and weight of vehicles [1].

Given this situation, the German automobile club ADAC (Allgemeiner Deutsche Automobil$\mathrm{Club}$ ) has long been calling for larger parking spaces in parking garages as well as in public urban space in the future, and the constant increase in the number of SUV registrations has only strengthened its case $[6,7]$.

As a result, the rising numbers in motorised individual transport have led to a more and more widespread private usurpation of public urban space, thus running counter to the guiding principle of a liveable city designed with people in mind [8]. Due to the one-sided pre-dominance of private cars, public urban space is not only divided up unfairly, but the increasing size of the vehicles also results in impaired visibility conditions, which have a negative impact on road safety. A steady increase in vehicle size therefore reduces both objective and subjective safety on the road. Reducing the size of vehicles lessens both the danger of accidents and the probability of serious consequences.

The feasibility study "EcoMobileum - Development of a World of Experience for Environmentally Friendly 4D Mobility in Cities", funded by the German Federal Environmental Foundation, DBU [9], has set itself the goal of reversing this causal relationship by promoting mobility with a decreased number of downsized, decelerated, decarbonized vehicles and initiating a path of sustainable development.

The four Ds form the counter-design to the current growth paradigm of "more, further faster", each of which is calculated in accordance with an appropriate degree of urban mobility:

- Downsizing: reducing vehicle size (exterior volume $\leq 5,000$ liter, unladen weight $\leq 750 \mathrm{~kg}$ ).

- Deceleration: reducing vehicle design speed $(80$ or $100 \mathrm{~km} / \mathrm{h}$ )

- Decrease: reducing the number of vehicles (max. 150 cars/1000 inhabitants)

- Decarbonisation: carbon neutral vehicles

The new traffic development based on $4 \mathrm{D}$ leads to increasing energy efficiency, resulting in a positive environmental balance sheet [10].

While there are already numerous technical innovations in the field of micromobility, light electric vehicles, light utility vehicles) [11] for almost all fields of application, its success depends on a change in people's mobility behaviour. This is where the idea of the EcoMobileum ${ }^{\circledR}$ [12-16] comes in, by making it possible to experience low-emission, low-noise and resource-saving types of mobility in the city. This is what makes the concept of the EcoMobileum particularly innovative, because "only a combination of technical solutions and behavioural changes" can succeed in reversing the trend towards more and more individual motorisation [17](p.19). By downsizing the means of transport and converting to non-motorised and electric drives, the EcoMobileum is conceptually designed to reduce the burden on the environment in cities and to contribute directly to the political goal of transforming mobility in Germany. 
If these conflicting developments are to be resolved politically in the future in favour of sustainable transport development, people have to be won over by being shown concrete alternatives. This is what the World of Experience of environmentally-friendly mobility in cities is intended to accomplish.

This paper starts from the proposed idea and concept of an EcoMobileum; puts it in the theoretical context of integrated transport planning; presents the results of the feasibility study in regard of the methodological approach, format and educational configuration of the EcoMobileum; and finally discusses the feasibility, effectiveness and implications of an implementation of the EcoMobileum. The conclusions highlight the key relevance of political will to the realization of EcoMobileums.

\section{Theoretical Framework}

The paradigm shift in transport planning towards sustainable mobility constitutes the theoretical framework of the EcoMobileum [18, 19]. Therefore, instead of focusing on traffic flow transport planning is dealing with people and their particular needs. In line with this paradigm, the previous focus on the requirements of the transport system has to be opened up and the needs of the people have to be taken into account more. This is justified by the fact that people are required to change their mobility behaviour in accordance with sustainable transport development and that transport planners are assigned the task of supporting them in this endeavour. An additional reason for transport planners to confer with citizens is the growing obstinacy of people in democratic societies. As a consequence, transport planning is increasingly confronted with the challenge of involving citizens in planning processes [20].

Here, we follow the approach of integrated transport planning, which distinguishes between three, mutually interdependent fields of action: (1) infrastructure management, (2) traffic management and (3) mobility management (cf. Figure 3). While infrastructure and traffic management constitute the fields of action of traditional transport planning, integrated transport planning expands its scope of action by adding mobility management, thereby including the social dimension. In all three fields of action, the aim is to cleverly combine attractive offerings with restrictive measures in order to achieve sustainable transport development. As David Banister points out: "The sustainable mobility approach requires actions to reduce the need to travel (fewer trips), to encourage modal shift, to reduce trip lengths and to encourage greater efficiency in the transport system" [18](75). 


\section{Integrated Transport Planning}

\begin{tabular}{|c|c|c|}
\hline Infrastructure & Traffic & Mobility \\
Management & Management & Management \\
\hline $\begin{array}{c}\text { structural } \\
\text { measures } \\
\text { (offerings) }\end{array}$ & $\begin{array}{c}\text { procedural } \\
\text { measures } \\
\text { (offerings) }\end{array}$ \\
\hline $\begin{array}{c}\text { structural } \\
\text { measures } \\
\text { (restrictions) }\end{array}$ & $\begin{array}{c}\text { operational } \\
\text { measures } \\
\text { (offerings) } \\
\text { measures } \\
\text { (restrictions) }\end{array}$ \\
\hline
\end{tabular}

Figure 3. The three areas of planning, including the dual measures within an integrated planning model [26](p.3).

Against this background, micro mobility forms a central building-block within the framework of an integrated transport development strategy, which breaks with the paradigm 'higher, further, faster' [21]. With micro mobility, the human scale finds its way into transport planning, the task of which is to create the conditions for people to successfully use the 'soft' transport modes (bicycles and pedestrian mobility) [22]. Through mobility management, integrated transport planning pursues the goal of communicating the transformation: "Transport planning must involve the people, so that there is an understanding of the rationale behind the policy changes and that behavioural change follows. Public acceptability is core to successful implementation of radical change, and it must involve community and stakeholder commitment to the process of discussion, decision-making and implementation" [18](75).

The EcoMobileum is intended to be the place where people can learn about the future of sustainable urban and transport development by experiencing micro-mobility in both senses of the word. To this end, we use the method of 'imagineering' developed by Walt Elias Disney for his theme parks: "The blending of creative imagination and technical know-how" [23](4). Accordingly, based on the rationale of the 'sustainable mobility paradigm', future urban spaces are designed for the new technologies of micromobility. While the Disney theme parks transport people into a dream world and thus pursue a private business model [24], the concept of the EcoMobileum is geared towards the goal of sustainability, which is a common good, thus representing the public interest.

\section{The concept of the EcoMobileum}

The EcoMobileum is based on three conceptual pillars that can be combined in different ways or configured as needed: (1) The Exhibition, (2) The Experience Park, (3) The Academy.

(1) The exhibition is intended to present the variety of not only well-known but also, in particular, innovative but still largely unknown forms of human-scale mobility. Centrally important is that the exhibition does not take on the character of a trade fair. Rather, 
all providers must comply with an overall concept that allows visitors to immerse themselves in everyday urban situations within the framework of a World of Experience. Accordingly, the set-up must allow visitors to try the products out in various real-life contexts.

(2) "Experiencing" the new mobility offerings in the Experience Park, which is designed with everyday life in mind, can be pursued by trying out vehicles on various test circuits, allowing visitors to evaluate and compare the vehicles' suitability for everyday use. For this purpose, (traffic) infrastructures must be offered that are as close to reality as possible, meeting the different requirements of various user groups.

(3) Lastly, various forms of knowledge-transfer will be offered in an Academy/School for Mobility. The concept of mobility education, as distinct from traffic and road-safety education, constitutes the unifying element. Didactically sophisticated formats will be used to convey an envisioned new culture of mobility, in which citizens learn to practise sustainable mobility in a self-determined fashion and in accordance with their respective needs.

In this triad, the EcoMobileum will enable visitors to familiarize themselves with new vehicles with human scale (exhibition), use the latter to experience new qualities of urban space and to experience a new conception of mobility (experience park) and to understand the connections between mobility, urban quality of life and global sustainability (academy).

For successful transport design, it is important to put in place intelligent combinations of so-called pull and push measures in all three areas of planning. On the one hand, this means convincing users of the attractiveness of sustainable means of transport (pull) and, on the other hand, discouraging them from using non-sustainable means of transport, by means of restrictive measures (push). While political policy is mostly limited to attractive pull measures (carrot), it has been shown time and again that sustainable transport development cannot be achieved without push measures (stick) [25]. In terms of infrastructure management, this could be implemented in the framework of the EcoMobileum's World of Experience, for example, by means of a traffic intersection situation designed in accordance with the principle of shared space, where all road users move around on equal terms and communicate with each other via eye contact. In this instance, infrastructure planning supports local mobility (walking and cycling), while the dominance of car traffic is curtailed. Traffic management, i.e. the organisation of traffic flows, could also enhance local mobility at intersections by means of traffic light cycles that favour pedestrians and cyclists. This, too, should be made tangible to visitors within the framework of the EcoMobileum's World of Experience, in order to acquaint them with a new culture of mobility.

While infrastructure and traffic are the two classic fields of action in transport planning, mobility management is a relatively new field. Mobility management is directed at people's travel needs and behaviour and its goal is to support them in sustainable mobility behaviour [24]. This can be accomplished through targeted measures in the aforementioned areas of infrastructure and traffic, but also through legal frameworks or financing mechanisms that create appropriate incentives or restrictions in each case. A further instrument of mobility management to influence people's mobility behaviour is to provide them with information that confronts them with the consequences of their unsustainable behaviour and educates them about the possibility of sustainable transport development. In this sense, a facility like the World of Experience of the EcoMobileum, which aims to convince visitors of the benefits of a new mobility culture, is a typical measure in mobility management. 


\section{Feasibility, effectiveness and implications of an implementation of the EcoMobileum}

Based on the paradigm shift in transport planning outlined above, the feasibility of idea and concept of the EcoMobileum were assessed in an academic study and evaluated by an expert advisory board. Within the framework of the study, two locations were examined for their suitability for an EcoMobileum. These are the heritage-protected former congress \& exhibition hall in Freiburg and a supermarket on the site of former US military barracks in Heidelberg. While site-specific concepts were developed for both locations, our article presents the overarching conceptual approach, which can be adapted to suit various conditions in terms of location and operational set-up.

The value of the EcoMobileum concept lies in its being attuned to current changes in mobility behaviour. More and more people are reassessing their mobility behaviour, including their choice of means of transport. For example, owning a car is no longer the first choice for everyone, especially in cities, and public transport, bicycles and various sharing services are becoming ever more popular. In view of this development and the ever-increasing willingness to explore new mobility alternatives for everyday life, the concept has the potential to make a significant contribution to the transformation of mobility. It is high time to respond to the citizens who are amenable to the coming inducements in this transformation. For the successful implementation of the concept, the contextual framework has to be examined, which we will do in part 4.

In light of the discrepancy between the programmatic aspirations of sustainable transport development and the actual growth dynamics in the automobile sector, the World of Experience for environmentally friendly mobility in cities can indeed significantly contribute to pointing out the alternatives and make it possible for people to experience them.

The study has explored the feasibility of a World of Experience for environmentally friendly mobility in cities and laid the foundations for its implementation. In terms of content, the project is guided by the principle of ecomobility (German equivalent: Umweltverbund) Ecomobility means the combination of walking, cycling, using a variety of small non-motorised or electrically motorised means of urban transport and public transport, thus ecological and concomitant economically mobility. The EcoMobileum focuses on small, environmentally friendly means of transport and mobility aids, covering the range "between shoes and the car". The number and variety of these means of transport is constantly increasing, as a survey of what is on offer shows. ${ }^{1}$ The aim of this concept is to determine how citizens can be familiarised with the assortment of environmentally friendly four-D vehicles by means of a permanent facility.

The World of Experience at the heart of this concept can effectively familiarise people with a sustainable urban mobility culture, based in particular on smaller and lighter vehicles and mobility aids. However, the change towards a people- and environmentally friendly mobility behaviour will not take place overnight: it requires a change in habitual mobility behaviour. New possibilities and spaces have to be opened up in order to be able to accommodate the guiding principle of the people-oriented city.

The idea of the EcoMobileum is acquainting people with new mobility by allowing them to experience these as yet unknown forms of mobility in as many places as possible. The long-term goal is therefore to provide every agglomeration with just such a place. These locations, serving as nuclei, will then be supplemented by modular and possibly mobile stations throughout Germany. This will draw attention to the EcoMobileum beyond the specific location and take pressure off the existing mobility services. The EcoMobileum is thus a place where information is

\footnotetext{
1 The Urban Idea has created a database that currently comprises around 700 vehicles and mobility aids for a highly diverse range of applications: https://www.theurbanidea.com/en/zwischen-schuh-und-auto
} 
provided for a better understanding of the effectiveness of new forms of mobility and $4 \mathrm{D}$ transport, as a way of alleviating the environmental burden on cities. The EcoMobileum makes it possible to experience, hands-on, new options in mobility. In doing so, it encourages citizens to change their behaviour and select modes of transport that are environmentally friendly. The strategic purpose is to familiarise people in a playful fashion with small, lightweight vehicles that can serve as an alternative to private cars, but without restricting their mobility.

In what follows, the EcoMobileum is contextualised from the point of view of integrated transport planning, in the context of the current challenges faced by urban transport development. The principal topics in urban transport development are the reallocation of public space, new transport offerings as discussed under the heading of "Mobility as a Service" (MaaS), as well as institutional reforms, as essential prerequisites for a reorganisation of traffic and mobility. In the context of the World of Experience offered by the EcoMobileum, the three thematic fields are corresponding to the three conceptual columns. Accordingly, the individual vehicles in the exhibition will be linked to the overarching theme of MaaS. The experience park will be used to thematise the new allocation of public urban space and to design the test circuits accordingly. Lastly, the Academy will discuss the necessary institutional reforms, such as developing new formats of public participation.

\subsection{The Exhibition: Mobility as a Service (MaaS)}

In cities world-wide new transport services have been introduced, so-called "sharing services", which can be advertised by private providers in public space and used by potential customers. While ten years ago these services were initially limited to car sharing, on offer in urban areas in recent years are mainly various micro-vehicles, varying in size between a shoe and a car. Due to the ambivalent experiences that cities and municipalities have had with private providers and their products in recent years, to some extent the evaluations of these new transport offerings also diverge widely $[27,28]$. While some see the small, light vehicles as an infantilisation of urban transport development and vehemently oppose them, others regards small as beautiful and associate them with the great hope of an alternative to the private car. Regardless of the respective assessment, there is now a broad consensus that a barely-regulated range of offerings from a multitude of competing private providers is not viable. Since many of the small, light vehicles are not integrated into an overall transport policy strategy designed to keep car traffic out of the city, these transport offerings have so far been used in addition to cars and have thus actually resulted in more traffic - "convenience mobility" [29]. As a first reaction to this unsatisfactory situation for cities and municipalities, municipal associations have taken the initiative and, together with some providers of new micro-vehicles, drafted the memorandum "Strengthening Local Mobility Together", in which a joint approach in terms of sustainable transport development was agreed on a voluntary basis [30].

A further, still-unsolved problem is the disparate provider landscape making it difficult for customers to keep track of what is available and forces them to become members of several associations if they want to use the full range of services. The platform economy has responded to this problem with the concept of "Mobility as a Service" (MaaS), which promises to offer services from various sources in a single place. "Mobility as a Service refers to the integration of different types of transport services into a single mobility service that is available as required. A single smartphone application provides access to different forms of mobility with a single payment channel. MaaS providers offer a highly diverse range of transport options, encompassing public transport, bicycles, cars or bike-sharing, taxi, car rental or hire, or a combination of these. New business models and new ways of organising and running different transport options are as much a part of the concepts behind MaaS as access to improved information about users and the demand for services" [31].

The high expectations associated with MaaS, however, are disproportionate to the still limited experience with the new concept [32], which is also defined in different ways and as a result 
remains decidedly vague [33]. By drawing on the aura of a concept which has not yet been proven, MaaS is reminiscent of a product that is being massively promoted in the expectation that it will establish itself in the market [34]. Accordingly, MaaS is viewed primarily from a business angle [35]. MaaS is described as a "business ecosystem", in which information and communication technologies are employed to establish business models in the field of new mobility services in the market [36]. From this perspective, the challenge for a successful MaaS is to create the right market incentives in order to establish a balance between supply and demand [37].

While the debate on the MaaS concept amongst researchers is currently dominated by a supply-oriented understanding of planning that follows the principle "the market knows best", we propose, by contrast, an integrated understanding of planning based on the conviction that planning must be oriented towards political and societal goals [38]. Accordingly, we assume that MaaS will only contribute to sustainable transport development if it is aligned with politicallydefined goals, established beforehand, and the mobility offerings are integrated into an overall concept, together with regulatory measures.

The EcoMobileum experience can be used to show that, if the political goal of sustainable transport development is to be achieved, MaaS, which has so far been technology-driven and characterised by a narrowly economic understanding of planning, must be developed further, however, in line with integrated transport policy and planning and incorporated into the framework of a mobility management based on scientific quality criteria [39]. An integrated MaaS platform that presents visitors with all the products on display could form the all-connecting "matrix" of the exhibition (cf. Fig. 4), so to speak.

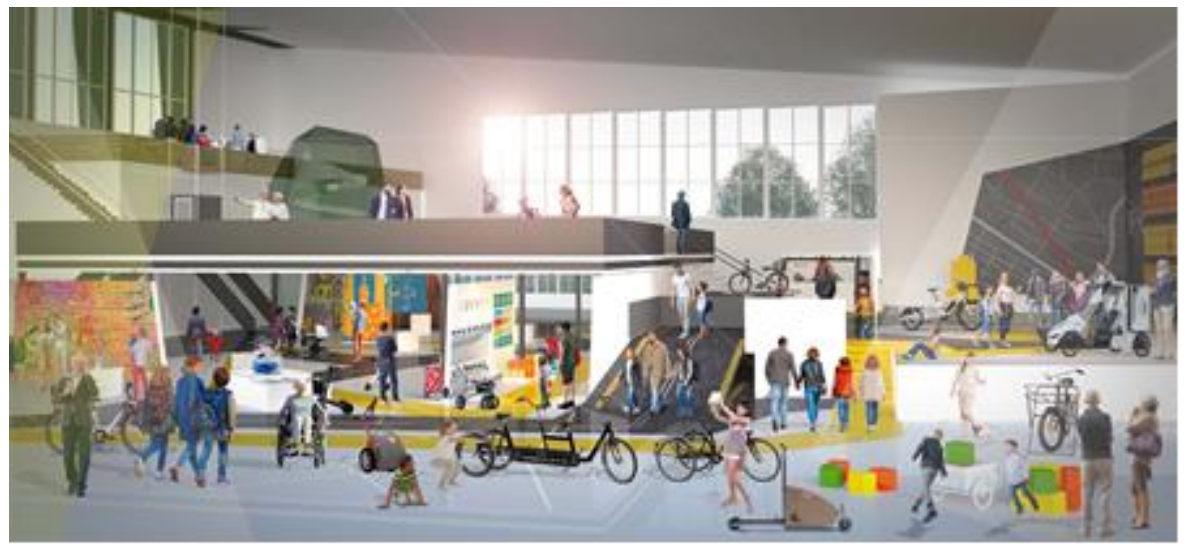

Figure 4: How the exhibition space in Freiburg's former congress \& exhibition hall could look like [9].

To this end, it would make sense to invite providers from the field of public transport who, in close cooperation with cities and municipalities, have always advocated an integrated citywide approach. An EcoMobileum in Berlin, for example, could use the successful Jelbi App of the Berlin Public Transport Authority, with which visitors could then make their way through the World of Experience. ${ }^{2}$

\subsection{The Experience Park: Redistribution of Public Space}

Debates regarding urban and transport planning have recently been increasingly marked by issues of equity that had not previously arisen [40]. Traditional transport planning has viewed urban space primarily as an obstacle to traffic that had be overcome as quickly as possible. Accordingly, transit spaces were created that existed solely to guide car traffic through the city as smoothly as possible. In addition, public urban space was generously allocated to stationary vehicles - for example, former market places were converted into parking lots. While for decades

2 https://www.jelbi.de/ 
parking private cars free of charge in public urban space was considered socially acceptable, this has now become an increasingly controversial topic of discussion.

Recently, the qualities of urban space have been rediscovered [41]. Most conspicuously, parking lots are being cleared of cars in order to restore them to their original function as market places. Under the heading of "environmental equity", the burdens placed by private cars on urban society are increasingly being thematised. The city of Berlin, for instance, has prepared a report on environmental equity that shows with great precision, district by district, which population groups are affected by air and noise pollution, have little green space and are affected by bio-climatic stress, and to what extent [42]. The report shows, for example, that socially disadvantaged people are disproportionately affected because they are reliant on low-rent housing located on busy roads. All in all, traffic is increasingly perceived by urban societies as detrimental to the health of the population and the quality of life [43].

On this backdrop the issue of equity and urban space in relation to traffic is increasingly being addressed. Apart from their detrimental effects on health, both moving traffic and parked vehicles occupy a comparatively large amount of public urban space. Figure 5 shows how much space is required by each mode for parking, moving $30 \mathrm{~km} / \mathrm{h}$, and $50 \mathrm{~km} / \mathrm{h}$. In terms of parked vehicles alone, a relatively small proportion of households with cars occupy by far the largest amount of public space (approx. 40/60). 


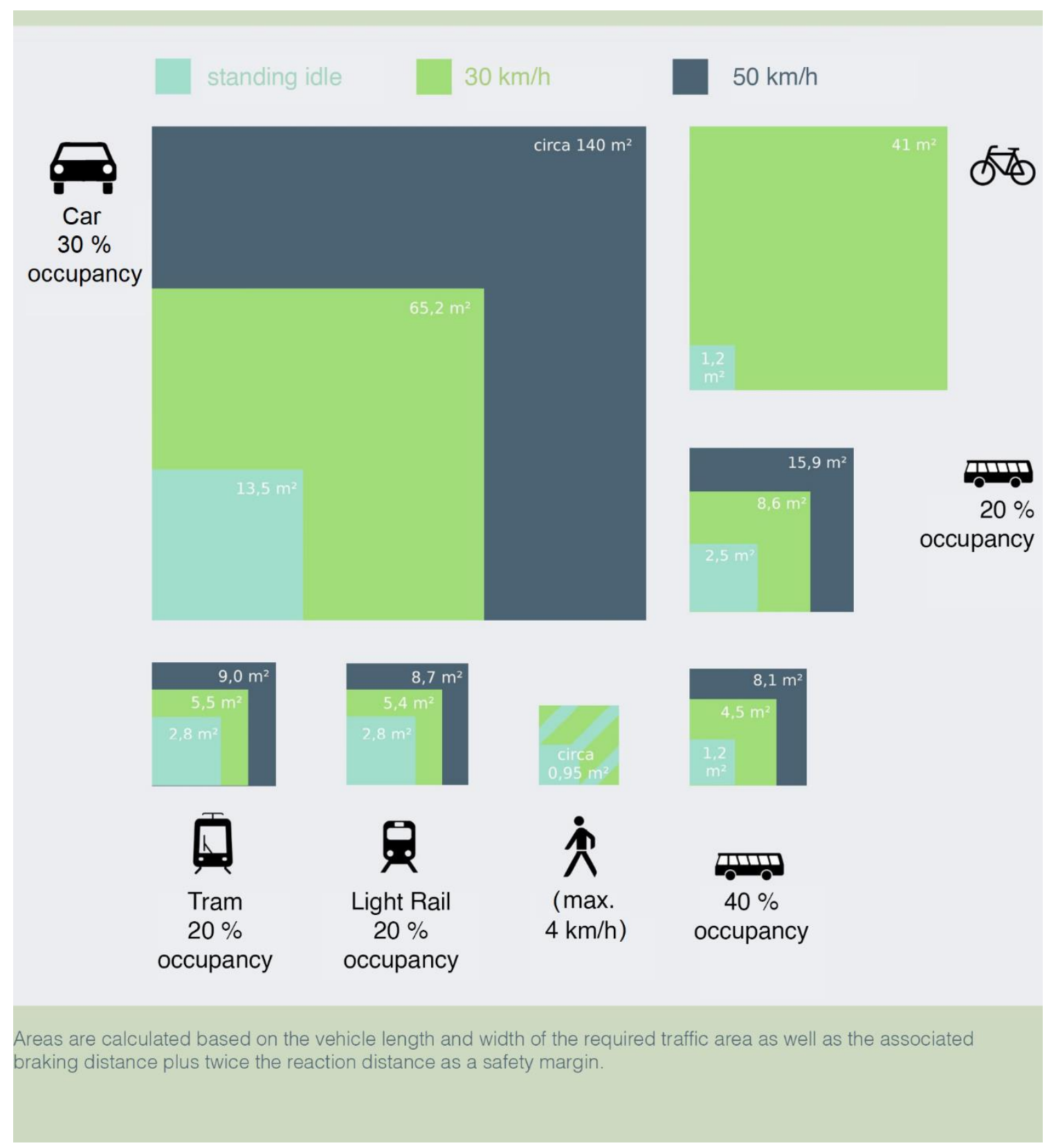

Figure 5: Comparison of the different space requirements of modes of transport, per person [44].

The transport infrastructure for moving car traffic has been expanded in recent decades at the expense of walking and cycling. As people reclaim urban space and other user groups such as pedestrians and cyclists make their voices heard, conflicts of use and thus demands for a reallocation of public urban space arise [45]. Traffic planners have reacted to this by changing the rules and regulations, which no longer stipulate that the street space be planned "inside-out", as it was in the past, where motorised road traffic was given priority, and the remaining space then allocated to pedestrians, cyclists and residents.

Instead, planning today should be done the other way around, by first taking into account the residents and their specific needs, setting the dimensions of the footpaths ac- 
cordingly and providing for an appropriate cycling infrastructure [46]. This new philosophy of planning is oriented towards the tangible requirements of local people and no longer towards abstract traffic flows as in the past, thus forcing a fair redistribution of public urban space.

The transformation of urban society through transport policy and planning as outlined here, with the redistribution of public urban space at the center, will require a conflict-ridden process of negotiation. The EcoMobileum could be the place where people get involved in this process. The test circuits in particular can be used to allow visitors to experience and evaluate new concepts of traffic planning and design of street space. Unlike traditional transport planning, integrated transport planning, with its focus on people and people-friendly urban transport, is dependent on citizens' involvement in processes of collaborative participation. The World of Experience of the EcoMobileum opens up the possibility of just such a transdisciplinary knowledge transfer, from which all participants benefit equally.

Using a possible location in Heidelberg, Germany as an example, the image below illustrates how test courses could be arranged around the exhibition hall, a former supermarket of the American forces. A mini parcours for bobbytrains, kids tricycles, walking bikes etc. would enjoy toddlers. The midi parcours would feature children's bikes, skates, inline skates and similar vehicles. A maxi parcours would be designed for trying out cargo bikes, recumbent tricycles, stand-up scooters, mobility scooters for seniors, multi-seater bicycles etc. Bicycles, footbikes, electric kick scooters and similar vehicles could be tested on a mobi parcours. Vehicles with speeds up to $45 \mathrm{~km} / \mathrm{h}$ such as s-pedelecs, e-motor scooters or electric mini cars would require a speedy parcours (or race course) with longer lanes and wider curve radius, which could also be used for speed contests as offers within programs for visitor groups. An urban parcours would feature impressions of urban spaces with narrow cycle lanes, intersections, pedestrian crossings, traffic lights, etc. Last not least, the functioning and usability of specific vehicles could be tested on a reality parcours with different surfaces (asphalt, cobble stone pavement, gravel, sand, etc.) as well as obstacles such as potholes, longitudinal grooves, manhole covers, tram tracks, sleepers, kerbstones, or ramps.

The variety of test tracks appears desirable to meet users' expectations of realistic vehicle testing conditions, to keep visitors of different physical conditions apart, to allow first-time experiences in a risk-free environment, and to accommodate high visitor numbers during peak attendance.

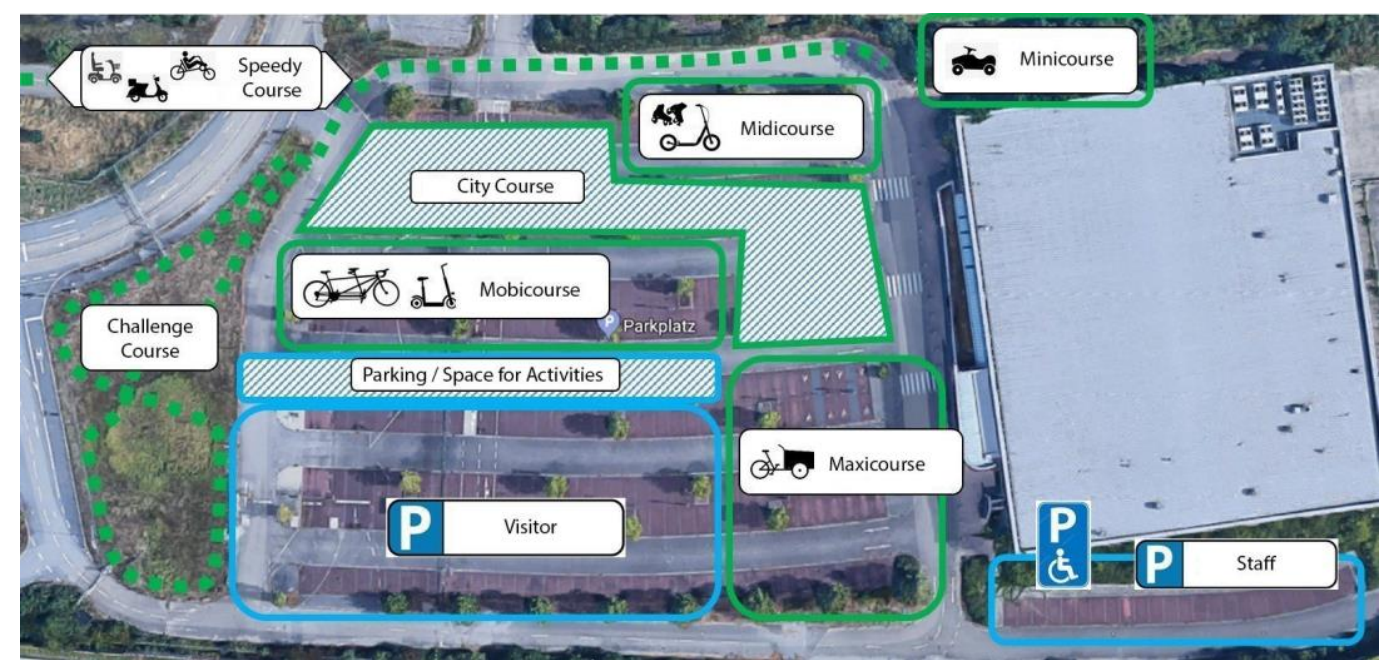

Figure 6: Possible arrangement of test circuits on the site of the former American supermarket at Patrick Henry Village in Heidelberg [9]. 
For example, the current debates amongst researchers on new designs for traffic intersections could be concretely and tangibly incorporated into the conceptualisation of the test circuits and "experienced" by the visitors with the new small-scale vehicles. It would furthermore allow researchers to apprehend the subjective perception of different design variations of public street space to a degree that is rarely possible within the framework of limited research projects In the service of informed decision-making, politicians, in turn, could make use of people's experiences by involving them in the contentious process of negotiating the redistribution of public street space and drawing on their native competence, instead of relying solely on an "expertocracy" as in the past [47]. Last not least, the everyday experiences made by visitors would allow the suppliers of new small and light vehicles to receive important feedback on how to improve their products, what would not be possible at a classic trade fair. The EcoMobileum experience is thus a multifaceted practical test that supports the impending transformation of urban society through transport policy and planning and innovations on the market, and thus makes a constructive contribution to actively and informatively shaping the aspired transformation of mobility.

\subsection{The Academy: Education in Mobility}

The perhaps greatest obstacle to sustainable transport development are the mental structures that have been well researched by social sciences, but have so far been neglected by transport researchers [48]. These structures encompass the everyday ideas about transport and mobility that each of us has internalised and that steer our behaviour. In Germany, as in most wealthy industrialised countries, these mental structures are strongly influenced by the private automobile, so that the "car ensconced in one's head" determines the idea of who is deemed to be mobile [49]. Accordingly, the ideal type of the mobile person is someone who owns a private car, preferably parked directly in front of his or her front door. In this situation, the car appears in the mind's eye for every planned activity and at the same time supplants alternative means of transport such as the bicycle or public transport. If, in addition, the alternative offerings become less attractive because demand for them is in decline, this effect is reinforced and people can claim, with good reason, that there is no suitable alternative to their private car. A life without the private car then seems less and less conceivable to them. Lastly, the aggregate actions of individuals shape our society as a whole, leading social scientists to speak of a "car society" [50].

Given this situation, the challenge of a future-oriented transport policy and planning based on alternatives to the private car is to address the mental structures that are onesidedly centred on the private car and to raise awareness of conceivable alternatives. This targeting of different population groups according to their respective demands and needs is the task of mobility management and one of its key instruments is mobility education. Unlike conventional traffic education, which follows a strategy of adaptation by training people to survive in the existing automobile traffic, mobility education aims to convey a broad understanding of traffic and mobility with the goal of providing support for mobility behaviour that is both self-confident and responsible [51]. The pioneer here is the German Federal State of Lower Saxony, where the Ministry of Education has developed an exemplary concept of mobility education and established a legally binding mobility curriculum for all educational institutions [52].

The EcoMobileum Academy can build on this and develop suitable educational offerings for different age groups. In particular, the practical modules of the mobility curriculum in Lower Saxony show how transport, traffic and mobility can be taught to younger age groups in a playful fashion. Strategically designed as a leisure facility, the EcoMobileum would have to develop the playful aspect even further and also develop appropriate media-based offerings in the sense of "gamification" for the older population 
groups. In the context of a World of Experience, the term "Academy" might imply negative connotations and, in the worst case, put people off. Therefore a different term should be considered, one that arouses the curiosity of all visitors and invites them to share their knowledge with each other rather than confronting them with a one-sided knowledge transfer. For example, visitors could be actively involved in planning processes and thereby receive fundamental information on the topic of sustainable transport development. Through media-based 3D support, they could, for instance, participate in designing a street space and become acquainted with the formal planning procedure. They would acquire knowledge empowering and encouraging them to apply their newly gained competence locally, and thus improve the quality of local transport policy and planning. Maybe this part of the EcoMobileum should not be called Academy but rather Mobility School (cf. Fig. 7).

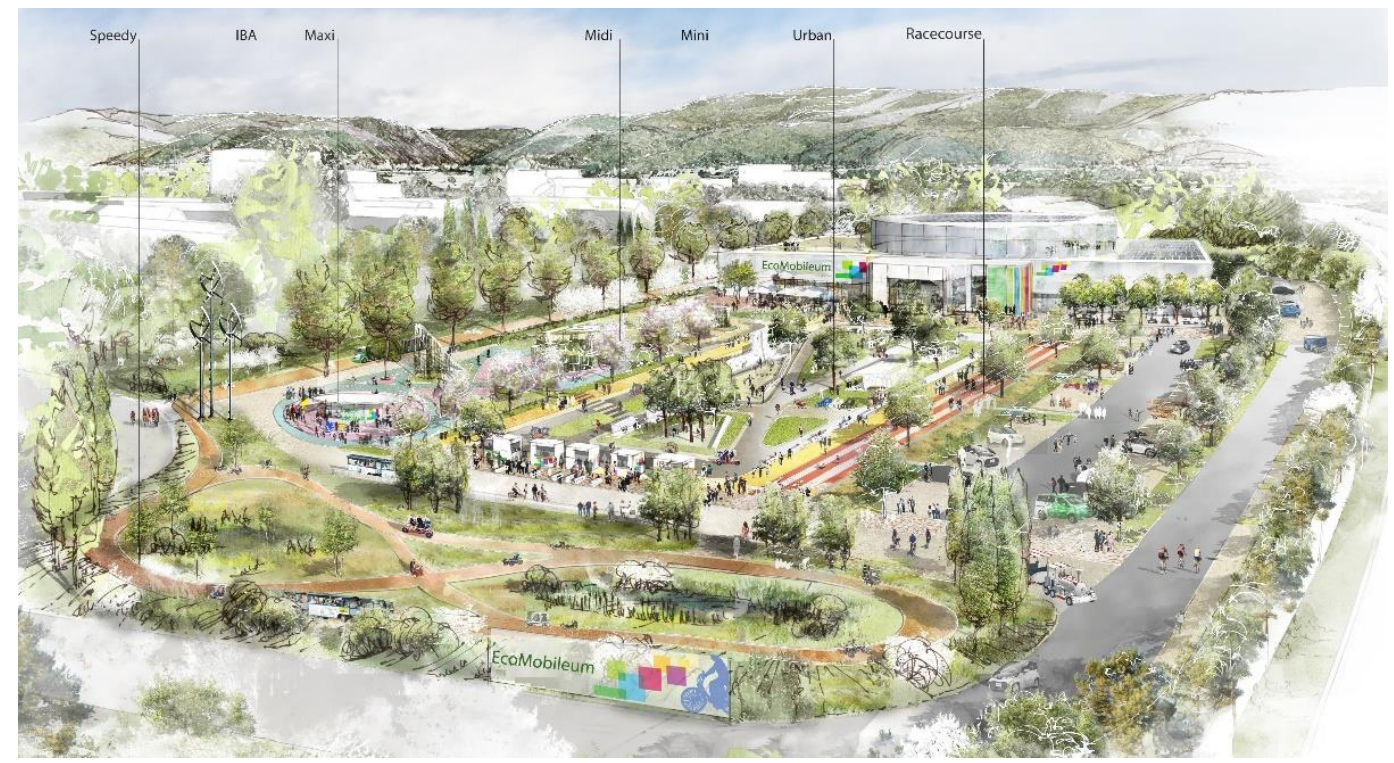

Figure. 7: Illustration of how the outdoor area in front of the former American supermarket in Heidelberg could look like [9].

Even if the name Academy was abandoned in favour of a broader concept, there should still be room for conventional educational offerings. In the background are the manifold obstructions to reform at the municipal level that still stand in the way of sustainable transport policy and planning [17]. The obstacles to the city of the future must be discussed more intensively in order to come up with appropriate solutions. Accordingly, the EcoMobileum should also provide opportunities for experts from politics, administration, business and research to exchange ideas and receive relevant training. At the same time, cities, towns and municipalities should be informed about what they can already implement today within the existing frameworks in terms of sustainable transport development [53]. An example of this is the Bicycle Academy financed by the German Federal Ministry of Transport, which is based at the German Institute of Urban Development and conducts training courses on cycling in cities, towns and municipalities throughout the country. By organising educational trips to the EcoMobileum, cities and municipalities could, for example, bring the opportunities for municipal action as compiled by Agora Verkehrswende to the attention of decision-makers in politics and administration [54].

In addition, the EcoMobileum's Mobility School could also be the contact point for traditional educational institutions such as day-care centres and schools, which would organise excursions there as part of their mobility education. In all cases one must ensure that the educational aspirations take playful but sophisticated, media-based forms. 


\subsection{The Costs: First Calculation}

Applying the Delphi technique, and involving the project's scientific advisor board as well as the members of the non-profit friends' association, we have come to sound estimates of the annual numbers of visitors that could be expected. According to our calculations the number of visitors during the first three years of operation could be in the range between 90,000 and 170,000, whereas it would increase to between 130,000 and 240,000 during long-term operation.

Based on an analysis of visitor entrance fees and exhibitor fees that could realistically be charged, our estimate of annual revenue lies between 1.7 and 2.25 million Euros, with 2.0 million Euros being a fairly realistic expectation.

We have calculated the expected annual costs of operation based on very detailed and realistic assumptions and arrived at 1.95 million Euros. Predominant cost items are the maintenance and regular renewal of the exhibition as well as test circuits, operational management and maintenance of the building(s) and outdoor space, as well as marketing, visitor service and programs/events/animation.

In any case, we are fairly confident that the EcoMobileum could be operated on a break-even basis.

\section{Conclusion: What counts is the political will!}

The EcoMobileum's World of Experience makes a vital contribution to the political goal of transforming mobility by countering the current trend of "more, further, faster" with the concept of contentment in urban mobility, which aims for less traffic, shorter distances travelled and at lower speeds. What makes the EcoMobileum special is that it doesn't merely postulate the mobility transformation, but also makes it possible for visitors to experience it. Everyone can gain an idea of possible versions of the future by trying out new means of transport and assessing their suitability for everyday use.

The EcoMobileum is not primarily centred on technical innovations per se; rather, new means of transport presented there serve to support a change in mobility behaviour. The EcoMobileum seeks to convey a new understanding of transport and mobility; its goal is thus social innovation. This is based on the insight that the great transformations of society in the past always involved a profound cultural change. The EcoMobileum seeks to support this cultural change by opening up spaces for its visitors to re-experience, re-imagine and re-think transport and mobility.

The EcoMobileum is an innovative approach to shaping the change towards a new culture of mobility in democratic societies and getting people involved in it. It enables visitors in various ways to actively shape cultural change. The insecurity often triggered by cultural change due to fears or anxieties in the face of the new and unknown and the resulting resistance to change can be constructively overcome by the EcoMobileum offering playful acquisition of experience. This makes the EcoMobileum an innovative contribution to the political legitimisation of sustainable transport development, which is dependent on people's informed acceptance today more than ever before.

The transformation to sustainable urban and transport development is an endeavour for the common good that has to be shaped by political policy. Unlike the Disney theme parks, whose business model is based on hedonistic consumption, politicians should use the concept of the EcoMobileum to develop the sustainable transformation of urban and transport development together with the citizens. In April 2021, the Federal Constitutional Court in Germany upheld the lawsuit lodged by Fridays for Future and reprimanded the Federal government for its lack of commitment to sustainable development. According to the Court, politicians are not meeting their social responsibility to protect the future of the young generation. We have calculated the cost of the annual maintenance of an EcoMobileum at about two million Euros; if implemented in all sixteen Federal states this would amount to an annual expenditure of 32 million Euros. Compared to the annual subsidies 
of 30 billion Euros misallocated in the transport sector, this is a perfectly affordable investment in the future.

\section{References}

1. UBA - German Environment Agency: Sustainable Mobility. Available online: https://www.umweltbundesamt.de/en/topics/transport-noise/sustainable-mobility

2. Authors' own calculation

3. Stephanowitz, J.; Zimmermann, K.; dpa; Reuters. Treibhausgase: Deutschland kann Klimaziele 2020 doch noch erreichen. Die Zeit [Online], March 16, 2020. Available online: https://www.zeit.de/wissen/umwelt/2020-03/treibhausgas-emission-svenjaschultze-klimaschutz (accessed on 6 April 2021).

4. Schwedes, O. Grundlagen der Verkehrspolitik und die Verkehrswende. In Energiewende: Eine sozialwissenschaftliche Einführung, 1st ed.; Radtke, J., Canzler, W., Eds.; Springer VS: Wiesbaden, Germany, 2020; pp 193-220, doi:10.1007/978-3-65826327-0_7.

5. Statista. Pkw-Bestand in Deutschland bis 2021. Available online: https://de.statista.com/statistik/daten/studie/12131/umfrage/pkw-bestand-in-deutschland/ (accessed on 30 March 2021).

6. Nobis, C.; Kuhnimhof, T.; Follmer, R.; Bäumer, M. Mobilität in Deutschland - MiD: Zeitreihenbericht 2002 - 2008 - 2017. Studie von infas, DLR, IVT und infas 360 im Auftrag des Bundesministeriums für Verkehr und digitale Infrastruktur; Bonn, Berlin, Germany, 2019.

7. Kilimann, S. Parkhäuser: 2,30 Meter Breite reicht modernen Autos kaum. Die Zeit [Online], December 20, 2012. Available online: https://www.zeit.de/auto/2012-12/parkhaus-suv-breiten (accessed on 6 April 2021).

8. Spelsberg, S. Kolumne Geht's Noch?: Allzu breit gemacht. taz [Online], November 30, 2018. Available online: https://taz.de/Kolumne-Gehts-Noch/!5552040/ (accessed on 6 April 2021).

9. Notz, J.N. Die Privatisierung öffentlichen Raums durch parkende Kfz: Von der Tragödie einer Allmende - über Ursache, Wirkung und Legitimation einer gemeinwohlschädigenden Regulierungspraxis; IVP-Discussion Paper No. 1, Berlin, Germany, 2017.

10. Otto-Zimmermann, K.; Schwedes, O. EcoMobileum - Machbarkeitsstudie zur Entwicklung einer Erlebniswelt für umweltfreundliche 4D-Mobilität in Städten, Berlin, Germany, 2020. Available online: https://www.ivp.tu-berlin.de/fileadmin/fg93/Forschung/Abschlussbericht_Machbarkeitsstudie_zur_Entwicklung_einer_Erlebniswelt_f\%C3\%BCr_umweltfreundliche_4-D_Mobilit\%C3\%A4t_in_St\%C3\%A4dten_AZ_3506701.pdf (accessed on 6 April 2021).

11. Croce, A. I., Musolino, G., Rindone, C., Vitetta, A. Sustainable mobility and energy resources: A quantitative assessment of transport services with electrical vehicles. Renewable and Sustainable Energy Reviews 2019, 113, 1-1.

12. Otto-Zimmermann, K. Time to question micromobility. Online supplement to Internationales Verkehrswesen $2 / 2021$

13. Otto-Zimmermann, K. EcoMobileum - Themenwelt „Mobilität zwischen Schuh und Auto“. Projekt eines Lern- und Erlebnisortes für Ökomobilität in Freiburg, Freiburg, Germany, 2016. Available online: https://www.theurbanidea.com/ecomobileum (accessed on 30 March 2021).

14. Otto-Zimmermann, K. EcoMobileum - Project of an international world of experience on urban ecomobility of tomorrow, Freiburg, Germany, 2018. Available online: https://www.theurbanidea.com/ecomobileum (accessed on 30 March 2021).

15. Otto-Zimmermann, K. EcoMobileum - Idee - Konzept - Entwicklung - Machbarkeit., Freiburg, Germany, 2020. Available online: https://www.theurbanidea.com/ecomobileum (accessed on 6 April 2021).

16. Otto-Zimmermann, K. EcoMobileum ${ }^{\circledR} /$ FROmobil ${ }^{\circledR}$ Erlebniswelt. Dokumentation zur Machbarkeit einer Erlebniswelt für nachhaltige städtische Mobilität. In EcoMobileum - Machbarkeitsstudie zur Entwicklung einer Erlebniswelt für umweltfreundliche 4D-Mobilität in Städten; Schwedes, O., Ed.; Berlin, Germany, 2020; pp 54-179.

17. Otto-Zimmermann, K.; Schwedes, O. EcoMobileum für Nachhaltige Mobilität. In: Veloplan 2/2021, 46-51

18. Ball, M.; Blümel, H.; Bormann, R.; Daubitz, S.; Holzapfel, H.; Klare, A.; Knieling, J.; Notz, N.; Rammert, A.; Ringwald, R.; et al. Hürden auf dem Weg zur Zukunftsstadt: Strategien für eine integrierte Stadt- und Verkehrspolitik. WISO Diskurs $2019,12$.

19. Banister, D. The sustainable mobility paradigm. Transport Policy 2008, 15, 73-80.

20. Litman, T. The New Transportation Planning Paradigm. ITE Journal 2013, 83, 20-28.

21. Grossardt, T.; Bailey, K. Transportation Planning and Public Participation: Theory, Process, and Practice; Elsevier: Amsterdam, Netherlands, 2018.

22. Schwedes, O.; Horr, Maximilian. Integrated Transport Planning: From Supply- to Demand-Oriented Planning. Considering the Benefits. Sustainability 2019, 11, 5900. https://doi.org/10.3390/su11215900

23. Cirianni, F.M.M.; Monterosso, C.; Panuccio, P; Rindone, C. A Review Methodology of Sustainable Urban Mobility Plans: Objectives and Actions to Promote Cycling and Pedestrian Mobility. In Smart and Sustainable Planning for Cities and Regions; Bisello A.; Vettorato D.; Laconte P.: Costa S. Eds.; Springer VS: Wiesbaden, Germany, 2018, pp 685-697, doi:10.1007/978-3-31975774-2_46.

24. Prosperi, L.J. The Imagineering Pyramid. Using Disney Theme Park Design Principles to Develop and Promote Your Creative Ideas; Theme Park Press: not stated.

25. Schaffer, S. Disney and the Imagineering of Histories. Postmodern Culture 1996, 6, 1-34. 
26. Piatkowksy, D. P.; Marshall, W. E.; Krizek, K. J. Carrots versus Sticks: Assessing Intervention Effectiveness and Implementation Challenges for Active Transport. Journal of Planning Education and Research 2019, 39, 50-64.

27. Schwedes, O.; Rammert, A. Mobilitätsmanagement: Ein neues Handlungsfeld Integrierter Verkehrsplanung, 1st ed.; Springer Fachmedien Wiesbaden; Imprint: Springer VS: Wiesbaden, Germany, 2020, doi:10.1007/978-3-658-30390-7.

28. Hamann, R.; Knöll, V.; Schimanski, T.; Schulz, S.; Bayer S. (E-)Kleinstfahrzeuge - Tech-Blase oder Verkehrsrevolution? Teil 1 Welches Potential haben "neue" vernetzte Mobilitätsangebote und welche Erfahrungen liegen vor? Internationales Verkehrswesen 2019, 3, 48-53.

29. Hamann, R.; Knöll, V.; Schimanski, T.; Schulz, S.; Bayer S. (E-)Kleinstfahrzeuge - Tech-Blase oder Verkehrsrevolution? Teil 2 Welches Potential haben die "neuen" vernetzten Mobilitätangebote in Deutschland? Internationales Verkehrswesen 2019, 4, 8085.

30. Civity. Urbane Mobilität im Umbruch? Available online: https://civity.de/de/matters/urbane-mobilit\%C3\%A4t-im-umbruch/ (accessed on 6 April 2021).

31. Deutscher Städtetag; Deutscher Städte- und Gemeindebund. Nahmobilität gemeinsam stärken - Memorandum of Understanding zwischen Deutscher Städtetag, Deutscher Städte- und Gemeinden und Anbietern von E-TretrollerVerleihsystemen, 2019. Available online: http://www.staedtetag.de/imperia/md/content/dst/2019/mou_e-tretroller_dst_dstgb_final.pdf. (accessed on 26 August 2019).

32. MAAS-Alliance. Mobility as a Service Alliance - MAAS-Alliance. Available online: https://maas-alliance.eu/ (accessed on 7 April 2021).

33. König, D.; Eckhardt, J.; Aapaoja, A.; Sochor, J.L.; Karlsson, M. Deliverable 3: Business and operator models for MaaS: MAASiFiE project funded by CEDR. Available online: https://www.cedr.eu/download/other_public_files/research_programme/call_2014/mobility_and_its/maasifie/cedr_mobility_MAASiFiE_deliverable_3_revised_final_2.pdf (accessed on 6 April 2021).

34. Utriainen, R.; Pöllänen, M. Review on mobility as a service in scientific publications. Research in Transportation Business \& Management 2018, 27, 15-23, doi:10.1016/j.rtbm.2018.10.005.

35. Giesecke, R.; Surakka, T.; Hakonen, M. Conceptualising Mobility as a Service. In 2016 Eleventh International Conference on Ecological Vehicles and Renewable Energies (EVER). 2016 Eleventh International Conference on Ecological Vehicles and Renewable Energies (EVER), Monte Carlo, Monaco, 06-08 Apr. 2016; IEEE, 2016 - 2016; pp 1-11, doi:10.1109/EVER.2016.7476443.

36. Smith, G.; Sochor, J.; Karlsson, I.M. Mobility as a Service: Development scenarios and implications for public transport. Research in Transportation Economics 2018, 69, 592-599, doi:10.1016/j.retrec.2018.04.001.

37. Proff, H.; Fojcik, T.M. Innovative Produkte und Dienstleistungen in der Mobilität: Technische und betriebswirtschaftliche Aspekte; Springer Gabler: Wiesbaden, Germany, 2017, doi:10.1007/978-3-658-18613-5.

38. Jittrapirom, P.; Caiati, V.; Feneri, A.M.; Ebrahimigharehbaghi, S.; González, M.J.A.; Narayan, J. Mobility as a Service: A Critical Review of Definitions, Assessments of Schemes, and Key Challenges. Urban Planning 2017, 2, 13-25, doi:10.17645/up.v2i2.931.

39. Docherty, I.; Marsden, G.; Anable, J. The governance of smart mobility. Transportation Research Part A: Policy and Practice 2018, 115, 114-125, doi:10.1016/j.tra.2017.09.012.

40. Schwedes, O.; Rammert, A. Was ist Integrierte Verkehrsplanung? Hintergründe und Perspektiven einer am Menschen orientierten Planung; IVP-Discussion Paper No. 2, Berlin, Germany, 2020.

41. Creutzig, F.; Javaid, A.; Soomauroo, Z.; Lohrey, S.; Milojevic-Dupont, N.; Ramakrishnan, A.; Sethi, M.; Liu, L.; Niamir, L.; Bren d'Amour, C.; et al. Fair street space allocation: ethical principles and empirical insights. Transport Reviews 2020, 40, 711-733, doi:10.1080/01441647.2020.1762795.

42. Havemann, A.; Selle, K. Plätze, Parks \& Co: Stadträume im Wandel; Analysen, Positionen und Konzepte; Rohn: Detmold, Germany 2010.

43. Senatsverwaltung für Umwelt, Verkehr und Klimaschutz. Basisbericht Umweltgerechtigkeit. Grundlagen für die sozialräumliche Umweltpolitik. Available online: https://www.berlin.de/sen/uvk/umwelt/nachhaltigkeit/umweltgerechtigkeit/ (accessed on 30 March 2021).

44. MacLaren, D.; Agyeman, J.: Sharing Cities: A Case for Truly Smart and Sustainable Cities. Cambridge, Massachusetts 2017.

45. Randelhoff, M. Vergleich unterschiedlicher Flächeninanspruchnahmen nach Verkehrsarten (pro Person). Available online: https://www.zukunft-mobilitaet.net/78246/analyse/flaechenbedarf-pkw-fahrrad-bus-strassenbahn-stadtbahn-fussgaengermetro-bremsverzoegerung-vergleich/ (accessed on 6 April 2021).

46. Adli, M. Stress and the City: Warum Städte uns krank machen. Und warum sie trotzdem gut für uns sind, 1st ed.; C. Bertelsmann: München, Germany, 2017.

47. Forschungsgesellschaft für Straßen- und Verkehrswesen. Richtlinien für die Anlage von Stadtstraßen: RASt 06; FGSV: Köln, Germany, 2007.

48. Fischer, F. Citizens, experts, and the environment: The politics of local knowledge, 4th ed.; Duke Univ. Press: Durham, London, $\mathrm{UK}, 2000$.

49. Welzer, H. Mentale Infrastrukturen: Wie das Wachstum in die Welt und in die Seelen kam; Heinrich-Böll-Stiftung: Berlin, Germany, 2011.

50. Canzler, W. Das Auto im Kopf und vor der Haustür: Zur Wechselbeziehung von Individualisierung und Autonutzung. Soziale Welt 2000, 2, 191-207.

51. Conley, J.; McLaren, A.T. Car troubles: Critical studies of automobility and auto-mobility; Routledge: London, UK, 2016, doi: $10.4324 / 9781315570846$. 
52. Schwedes, O.; Pech, D.; Becker, J.; Röll, V.; Stage, D.; Stiller, J. Von der Verkehrserziehung zur Mobilitätsbildung; IVP-Discussion Paper No. 2, Berlin, Germany, 2021.

53. Niedersächsisches Kultusministerium. Mobilität: Das Curriculum Mobilität. Available online: https://www.mk.niedersachsen.de/startseite/schule/schulerinnen_und_schuler_eltern/mobilitat/mobilitaet-106518.html (accessed on 7 April 2021).

54. Behrendt, S.; Bormann, R.; Faber, W.; Jurisch, S.; Kollosche, I.; Kucz, I.; Müller, D.; Rammler, S. Mobilitätsdienstleistungen gestalten: Beschäftigung, Verteilungsgerechtigkeit, Zugangschancen sichern. WISO Diskurs 2020, 4.

55. Agora Verkehrswende. Öffentlicher Raum ist mehr wert: Ein Rechtsgutachten zu den Handlungsspielräumen in Kommunen. Available online: https://www.agora-verkehrswende.de/fileadmin/Projekte/2018/OEffentlicher_Raum_ist_mehr_wert/Agora_Verkehrswende_Rechtsgutachten_oeffentlicher_Raum.pdf (accessed on 6 April 2021).

Funding: This research was funded by The German Federal Environmental Foundation, grant number AZ 35067/01.

Data Availability Statement: The office The Urban Idea generated a database with up-to-date 700 vehicles with a wide range for application: https://www.theurbanidea.com/zwischen-schuh-und-auto.

The final report with all concept studies is to be found here: https://www.ivp.tu-berlin.de/AB Machbarkeitsstudie

Conflicts of Interest: The authors declare no conflict of interest. The funders had no role in the design of the study; in the collection, analyses, or interpretation of data; in the writing of the manuscript, or in the decision to publish the results. 